\title{
EL DETERIORO AMBIENTAL ¿ES UNA ENFERMEDAD DESATENDIDA?
}

Lic. Manuel Osvaldo Arbino ${ }^{1}$, Dra. Elena Beatriz Oscherov ${ }^{2}$

Palabras claves: Salud ambiental - Enfermedades olvidadas - Contaminación

\section{RESUMEN}

$\mathrm{El}$ ambiente es un sistema vivo y complejo, expuesto a modificaciones y agresiones. El objetivo de este trabajo es valorizar al ambiente como una entidad capaz de enfermar y por lo tanto ser transmisor de patógenos al hombre y los animales. Se habla de "Enfermedades desatendidas u olvidadas", a aquellas enfermedades, como las parasitosis, Mal de Chagas-Mazza o Leishmaniosis, que afectan principalmente a poblaciones de escasos recursos en todo el mundo, que persisten mientras haya pobreza y desatendidas principalmente porque los afectados tienen escasa o nula influencia en las prioridades de la salud pública. Consideramos que en nuestra región, el deterioro ambiental es una de principales enfermedades desatendidas y por lo tanto deberían definirse en forma urgente políticas que prioricen la salud ambiental como una de las principales estrategias para búsqueda y el mantenimiento de la salud humana.

Si consideramos al ambiente como un sistema vivo y complejo, expuesto a modificaciones y agresiones, podemos suponer que puede deteriorarse y si no está agotada su capacidad de resiliencia, puede recuperarse. El objetivo de este trabajo es valorizar al ambiente como una entidad capaz de enfermar y por lo tanto ser transmisor de patógenos al hombre y sus animales. Es entonces necesario definir que entendemos por salud, por ambiente y por salud ambiental.

\section{Salud, ambiente y salud ambiental}

En una etapa primitiva del pensamiento humano, el concepto de salud se relacionó con la magia. El pensamiento mágico fue la principal herramienta para explicar las alteraciones del funcionamiento del cuerpo. Podemos calificar al concepto de salud en esta primera etapa como concepto mágico, ya que, en este nivel del desarrollo del conocimiento humano, el hombre acudió a la magia para explicar la realidad de su entorno y dominar los fenómenos de la naturaleza para su beneficio y seguridad. Este concepto aún persiste en nuestros días en algunas creencias populares, como por ejemplo "el mal de ojos" u "ojeada" según la cual una persona es capaz de producir mal con solo mirar.

Mediante el pensamiento mágico, el hombre considera que esos estados de alteración o "enfermedad", de causa no recono-

${ }^{1}$ Biología de los Invertebrados. Departamento de Biología. FACENA. UNNE. e-mail: osvaarb@gmail.com Tel: 0379 4457950, Interno 402

${ }^{2}$ Biología de los Artrópodos y Proyecto Salud Ambiental:Salud Humana. Programa UNNE Salud. Departamento de Biología. FACENA. UNNE.e-mail: eboscherov@yahoo.com.ar Tel: 0379 4457950, Interno 419 
cible, provienen de la acción de otras fuerzas de la naturaleza cuyos espíritus compiten con él, agrediéndolo y causándole daño; por esto necesita crear mecanismos que le permitan contrarrestar esas fuerzas malignas o invocar, en su apoyo, otras que le sean favorables; lo hace generalmente mediante procedimientos también mágicos que en cada cultura adoptan símbolos y rituales propios y específicos. Basta mirar las ofertas en los medios gráficos que van desde la lectura del Tarot a brujería blanca y negra y la existencia de curanderos, para aceptar que esta concepción está muy arraigada en la sociedad.

Con el desarrollo de las religiones surge el concepto de la enfermedad como un castigo o un producto de la influencia de espíritus demoníacos, que debe ser contrarrestado mediante prácticas religiosas. Así, a lo largo de la historia, el cuidado de los enfermos y en especial de los mentales, estuvo a cargo de los sacerdotes. La concepción religiosa sobre la enfermedad persiste en la sociedad actual y es así que existen los "manos santas", "sanadores" y centros de sanación tanto legítimos como ficticios.

Con el avance de la ciencia se relacionó las alteraciones físicas con las orgánicas y la salud pasó a definirse como la ausencia de la enfermedad. Esta corriente del pensamiento médico, tiene gran influencia en la sociedad y continúa imponiendo una ideología de la salud basada en el manejo de la enfermedad y no en la medicina preventiva y la importancia sociológica respecto del quehacer en salud, desarticulando la medicina de un análisis integral.

La ciencia ha permitido profundizar en el conocimiento de la enfermedad, desentrañando sus causas aparentes y conformando un enorme acervo de conocimien- to etiológico y terapéutico que, de alguna manera, ha conducido al sistema médico a la tendencia exagerada por la curación a ultranza, con un abandono casi inconsciente por el hombre y su contexto familiar, psicológico y social, en el cual está necesariamente inmerso sea cual sea su condición de enfermo, convaleciente o sano.

En el presente siglo se ha dado un interesante impulso a la discusión sobre el concepto de salud y se ha avanzado en la conformación de una teoría más integral que busca trascender el abordaje meramente biológico de la enfermedad para entender la salud humana, sin tener que partir de su contrario, la enfermedad o la afección, para definirla.

Como una concepción superadora, la Organización Mundial de la Salud (OMS), define a la salud como el perfecto bienestar físico, mental y social de un individuo. $Y$ en la Carta de Ottawa se sostiene que "para alcanzar un estado adecuado de bienestar físico, mental y social un individuo o grupo debe ser capaz de identificar y realizar sus aspiraciones, de satisfacer sus necesidades y de cambiar o adaptarse al medio ambiente. La salud se percibe pues, no como el objetivo, sino como la fuente de riqueza de la vida cotidiana. Se trata por tanto de un concepto positivo que acentúa los recursos sociales y personales así como las aptitudes físicas".

Desde el punto de vista de la Ecología la "salud es el equilibrio que se da entre el agente, el huésped y el medio ambiente". Estos tres factores integran la "Triada Ecológica".

El hombre es el huésped en esta definición, concebido como el individuo ubicado en un ambiente sujeto a las acciones de los diferentes agentes y, por eso, susceptible de 
sufrir enfermedad. El huésped cuenta con muchos factores que lo hacen susceptible o resistente a sufrir enfermedades; los principales son: La edad, la raza, el sexo, el estado inmunológico y los procesos metabólicos; todos estos factores no actúan aisladamente sino interrelacionados. $\mathrm{El}$ agente es el elemento que puede causar lesiones $y$ enfermedad; en la naturaleza encontramos agentes físicos, químicos y biológicos.

$\mathrm{El}$ ambiente es el conjunto de todas las condiciones externas e influencias a las cuales un sistema está sometido.Para el hombre, el ambiente incluye al familiar, el escolar, el cultural, el laboral, el recreativo, el deportivo y el geográfico. El ambiente familiar puede afectar psicológicamente o físicamente la salud por el comportamiento de los miembros de la familia, sus creencias y sus mitos. En el ambiente escolar existen muchos factores que junto con los familiares, pueden lesionar la integridad física y mental. En el medio laboral hay una gran cantidad de riesgos que llevan a las personas a sufrir accidentes o a padecer enfermedades profesionales.

Además, accidentes e incidentes en el medio laboral pueden afectar el medio externo adyacente, como ocurren con desastres asociados con la industria, que causan grandes daños en el ambiente y en el ecosistema. La fuga de gas con dioxina en Seveso en 1976; el incendio y descarga de aguas contaminadas al Rhin, provenientes de una bodega de Basilea en 1986; y recientemente el derrame de cianuro de la mina Veladero en San Juan, Argentina tal como se desprende de un informe del Instituto del Medio Ambiente de la UNCuyo (2015) o la ruptura de dos represas que contenían desechos tóxicos de una empresa minera en el sureste de Brasil, en la región central de Minas Gerais (noviembre de 2015), son algunos ejemplos.
Son también factores de alto riesgo los desastres naturales como las tormentas y los huracanes, las avalanchas derivadas de las crecientes de algunos ríos (en octubre de 2015, parte de un cerro de unos 100 metros de altura colapsó y arrasó con la humilde localidad de Santa Catarina Pinula, 15 kilómetros al sur de Ciudad de Guatemala) o terremotos en las zonas volcánicas (sismo en 8,4 grados en Chile en Septiembre de 2015). Pero además del peligro que implica los desplazamientos de la corteza terrestre, las erupciones volcánicas con la consecuente lluvia de cenizas es la que abarca una mayor superficie y afecta a un mayor número de personas y bienes materiales.

La salud ambiental ha sido definida por la OMS como la rama de la salud pública que se ocupa de las formas de vida, las sustancias, las fuerzas y las condiciones del entorno del hombre, que pueden ejercer influencia sobre su salud y bienestar. Este concepto de salud ambiental está íntimamente ligado a los de medio ambiente, ecología y riesgo. Se entiende por riesgo la probabilidad de daño, enfermedad o muerte bajo circunstancias específicas.

En la Constitución Nacional se reconoce la idea de ambiente saludable al establecer que un ambiente sano, equilibrado y apto para el desarrollo humano es un derecho (Artículos 41 al 43).

\section{¿Por qué enferma el ambiente?}

El deterioro de la salud ambiental se produce por acción antrópica, principalmente en los centros urbanos, pero también en los ambientes naturales por la utilización de agroquímicos, explotaciones de minerales, etc. En las ciudades el principal agente de contaminación son los residuos acumu- 
lados en la vía pública, baldíos y lugares de esparcimiento, cuyo efecto nocivo va desde permitir el desarrollo de roedores e insectos vectores de patógenos hasta la dispersión de tóxicos, producción de olores desagradables y contaminación visual. Pero también contribuye el descuido de los patios y jardines en las viviendas, en donde se acumulan materia orgánica y recipientes en desuso.

La basura es un grave problema que se acrecienta día a día, tanto para comunidades pequeñas, como para las grandes ciudades, pero en éstas el problema es mayor debido al continuo aumento de la población urbana, especialmente por la migración hacia ellas, de habitantes de poblados chicos o comunidades rurales en busca de una mejor calidad de vida, primordialmente en países subdesarrollados o en vías de desarrollo y que da como resultado una urbanización sin planificación. También las actividades humanas modernas y el desmesurado consumismo acrecientan en forma exponencial la cantidad de basura que se genera.

La palabra basura proviene del latín *versüra, derivado de verrère, que significa "barrer". Por esto se puede decir que el significado original fue "lo que se ha barrido". Podemos considerar como basura a los desechos producto de la actividad humana, que carecen de valor o utilidad directa o indirecta para el hombre. Actualmente, se usa ese término solo para denominar aquella fracción de residuos que no son aprovechables y que por lo tanto debería ser tratada y dispuesta para evitar problemas sanitarios o ambientales.

Se denomina contaminación ambiental a la presencia en el ambiente de cualquier agente (físico, químico o biológico) o bien de una combinación de varios agentes, en lugares, formas y concentraciones tales que sean o puedan ser nocivos para la salud, la seguridad o para el bienestar de la población, o bien, que puedan ser perjudiciales para la vida vegetal o animal, o impidan el uso normal de las propiedades y lugares de recreación y goce de los mismos. Los tipos de contaminación más importantes son los que afectan a los recursos naturales básicos: el aire, los suelos y el agua. Algunas de las alteraciones medioambientales más graves e indudablemente relacionadas con los fenómenos de contaminación son los escapes radiactivos, el smog, el efecto invernadero, la lluvia ácida, la destrucción de la capa de ozono, la eutrofización de las aguas o las mareas negras; pero hay otras consecuencias menos evidentes y generalmente a largo plazo que pueden afectar la salud humana y animal, como las enfermedades y alteraciones genéticas graves.

Entre las enfermedades que pueden ser causadas en forma directa o indirecta por la contaminación ambiental, están las infecciones respiratorias e intestinales, las afecciones cutáneas, otitis media aguda, conjuntivitis, neumonías y bronconeumonías, gripe, disenterías, cólera, hepatitis, dengue clásico y dengue hemorrágico e intoxicación por plaguicidas.

En las ciudades y pueblos, una fuente importante de contaminación es la materia fecal de los perros. Son tres los factores principales que inciden: 1) el aumento constante de las poblaciones de perros abandonados en la vía pública. 2) familias con una cantidad de perros que no pueden mantener y dejan libres en las calles para que busquen su alimento y 3) en los últimos años, la actividad de los "pasea-perros", personas que realizan su labor en la mayoría de los casos, irresponsablemente, sin reco- 
ger las heces que los animales eliminan.

Los edificios de viviendas colectivas favorecen una mayor concentración de la población y de sus animales domésticos. A las mascotas se les permite el acceso a las aceras y áreas de recreación y muy pocas personas tiene la cultura de recoger las excretas producidas por sus perros. A su vez, en los barrios periféricos, los niños de corta edad pueden defecar en el suelo, facilitando así la propagación de los enteroparásitos, los que ingresan a nuevos hospedadores mediante la contaminación de agua y alimentos (transmisión feco-oral).

Existen diferentes tipos de parásitos, entre los que se cuentan los geohelmintos. Estos organismos se denominan así porque parte de su ciclo (huevos y/o larvas) viven en el suelo. Como ejemplo se pueden citar a los parásitos humanos: Ascaris lumbricoides, Ancylostoma duodenale y Necator americanus y a los del perro: Ancylostoma caninum y Toxocara canis. Estos parásitos viven en el intestino de sus hospedadores (enteroparásitos) y sus huevos salen al exterior con las heces, contaminado así el suelo.

La materia fecal de los animales, especialmente la de los perros, son considerados contaminantes biológicos por contener en muchos casos las fases de transmisión de parásitos, que pueden ser zoonóticos. Para que se vuelvan infestantes deben madurar durante un tiempo variable según la especie y las condiciones climáticas, de ahí que la falta de responsabilidad en el manejo de las excretas posibilita que se cierre el ciclo biológico de dichos parásitos.

Si bien los determinantes del deterioro ambiental son complejos, en la ciudad de Corrientes, y posiblemente lo mismo ocurra en diferentes ciudades y pueblos de Argentina, se pudieron identificar dos causas principales del deterioro ambiental: por un lado el sistema de recolección municipal de residuos, que solo se efectúa en determinadas calles y en forma discontinua (contraviniendo las mismas disposiciones municipales), esta situación provoca que los vecinos se sientan justificados por arrojar en las esquina o sitios baldíos los desperdicios domiciliarios, sin respetar horarios y mínimas normas de convivencia. Por otra parte, no se plantean acciones comunitarias para mantener la limpieza del entorno ya que no se asume como un problema que debe ser resuelto no solamente por los organismos públicos, si no por los mismos habitantes.

De todos modos, en los últimos años, algunos sectores de la sociedad han comenzado con la reutilización y el procesamiento de la basura a nivel casero, ciertos municipios han encarado proyectos serios de separación, tratamiento y reciclaje de residuos urbanos y en la actividad privada algunas empresas realizan importantes inversiones para el reciclado de papeles, metales o desechos orgánicos de los productos que procesan. Otras actividades, como los emprendimientos de turismo ecológico encarados por algunas comunas y privados o el Tecnotren, ideado por un trabajador ferroviario jubilado, que circula por vías abandonadas en la provincia de Entre Ríos son pequeñas muestras de cómo podemos participar en la búsqueda de un ambiente sano.

Otro factor positivo que hay que considerar es que amplios sectores de la población están tomando conciencia del peligro que lleva convivir con la basura, así como los sectores más vulnerables comienzan a reclamar que el Estado les garantice vivir en un ambiente saludable, lo que implica 
no solamente un sistema de recolección de residuos sistematizado, sino también la provisión de agua potable, el adecuado tratamiento de las excretas, el entubado de desagües pluviales o su mantenimiento y la exigencia a los propietarios de mantener los sitios baldíos desmalezados y limpios.

Pero si bien estas acciones, aisladas, muchas veces voluntariosas, permiten vislumbrar un mayor compromiso de la sociedad en la búsqueda de un ambiente más vivible, todavía en Argentina, el control sobre las grandes Industrias que vierten al ambiente enormes cantidades de desechos contaminantes al aire, al suelo o el agua, es escaso o nulo.

En la literatura y en Jornadas Científicas se habla de las "Enfermedades desatendidas u olvidadas", relacionando con este concepto a aquellas enfermedades, como la enfermedad de Chagas-Mazza o la leishmaniosis mucocutánea o el dengue, que afectan principalmente a poblaciones de escasos recursos, que viven en barrios o

\section{BIBLIOGRAFÍA}

Alfonso C R. Componentes de la salud ambiental. Instituto Nacional de Higiene, Epidemiología y Microbiología Cuba.

Manrique Abril F. G. 2015. Una aproximación al concepto salud enfermedad. http//www. un.docentes.unal.edu.co. (Consultado el 30 de septiembre, 2015)

OMS. 1946. Preámbulo de la Constitución de la Asamblea Mundial de la Salud, adoptada por la Conferencia Sanitaria Internacional, Nueva York. Actas oficiales de la Organización Mundial de la Salud, No. 2. 100 pp.

OPS.1987. Carta de Ottawa para la Promoción de la Salud. www.busde.paho.org. (Consultado el 20 de agosto, 2015) zonas marginales urbanas o rurales de países subdesarrollados o en vías de desarrollo, en entornos de extrema pobreza. Enfermedades que van a persistir mientras haya pobreza; enfermedades que en otros lugares del mundo han desaparecido en forma gradual, paralelamente con la mejora del nivel de vida y la higiene personal y del entorno. Otra de las causas por la que son enfermedades desatendidas, es porque la mayor parte de las personas afectadas por estas enfermedades, por su condición socioeconómica, tienen escasa o nula influencia en las prioridades de la salud pública.

La falta de compromiso, tanto individual como colectivo, el hecho de que la educación ambiental no es considerada como prioridad y que no se cumple la legislación vigente, lleva a concluir que el ambiente enfermo es una de las enfermedades más desatendidas de nuestra región y por lo tanto deberían definirse en forma urgente políticas que prioricen la salud ambiental como una de las principales

Milano Alicia. M. F.; E. B. Oscherov. 2002. Contaminación por parásitos caninos de importancia zoonótica en playas de la Ciudad de Corrientes. Parasitología Latinoamericana. 57 (3 -4): $119-123$

Milano, A. M. F., Oscherov E. B. 2005. Contaminación de aceras con enteroparásitos caninos en Corrientes, Argentina. Parasitología Latinoamericana. 60 (1-2): 82-85

Ordóñez G. A. 2000.Rev Panam Salud Publica/Pan Am J Public Health 7(3), 137-147 